\title{
O PERFIL DO CURSO DE GESTÃO DE TURISMO DO CEFET NO POLO DE EDUCAÇÃO À DISTÂNCIA ROCINHA
}

\author{
RIO DE JANEIRO/RJ MAIO/2018
}

\author{
Maria Campobelo da Silva - CEFET - mycampobelo@gmail.com \\ Fabio Vinicius de Araujo Passos - CEFET - fabioturis@gmail.com \\ Elizabeth Freitas Rodrigues - CEFET - efreitasr@gmail.com \\ Maria Campobelo da Silva - CEFET - mycampobelo@gmail.com
}

Tipo: Investigação Científica (IC)

Natureza: Descrição de Projeto em Andamento

Categoria: Pesquisa e Avaliação

Setor Educacional: EDUCAÇÃO SUPERIOR

\begin{abstract}
RESUMO
Esse artigo tem como finalidade conhecer o perfil dos Curso de Tecnologia de Gestão em Turismo TGT - do Centro Federal de Educação Tecnológica Celso Suckow da Fonseca - CEFET-RJ oferecido pelo Consórcio Cederj, no Polo Rocinha, no Município do Rio de Janeiro - RJ. A pesquisa deu-se metodologicamente pelo levantamento bibliográfico documental e pesquisa de campo utilizando a metodologia de pesquisa pesquisa exploratória. Foi realizada uma pesquisa com a intenção de conhecer melhor o funcionamento curso de TGT no Polo de Educação à Distância localizado no Bairro de São Conrado no Município do Rio de Janeiro. Partindo da premissa que o turismo é um fenômeno que cada vez mais deve ser estudado e analisado a fim de identificar os múltiplos componentes em suas inter relações de causas e efeitos. Com base nestes procedimentos, contextualiza-se conceitualmente sobre a Educação à Distância, e o Consórcio Cederj com a oferta de seus cursos em diversos municípios, oferecendo o estudo gratuito de graduação no Estado do Rio de Janeiro.
\end{abstract}

Palavras-chave: Educação a Distância; Cederj; Rocinha; Turismo. 


\section{Introdução}

A Educação à Distância - EaD é formada por diversas gerações e no processo de regularização, no entanto ainda não se tem um estudo concreto sobre o perfil dos alunos dessa modalidade. De acordo com o Censo EaD. BR, da Associação Brasileira de Educação a Distância - ABED, realizado em 2012, o quantitativo de alunos de educação a distância são na maioria mulheres entre 18 e 30 anos.

Conforme relata a coordenadora Ivete Pelange, nos anos anteriores os estudantes eram mais maduros e atualmente não sabemos as causas dessas mudanças de perfil. Percebe-se que cada vez mais os jovens estão conectados à tecnologia.

Em conformidade com a pesquisa no Instituto Nacional de Pesquisas Educacionais Anísio Teixeira - INEP, em 2014 existiam mais de 1,2 mil cursos à distância no Brasil, sendo as universidades responsáveis por $90 \%$ da oferta. Ainda com estudo nessa mesma pesquisa foi constatado um crescimento de 49 mil para 1,1 milhão para os alunos EaD.

De acordo com Bielschowsky (2017), o Centro de Educação a Distância do Estado do Rio de Janeiro - RJ - CEDERJ teve seu início planejado em 1999 na Secretaria de Estado de Ciência e Tecnologia do Estado do Rio de Janeiro.

Bielschowsky, usufruindo como inspiração a percepção do professor Darcy Ribeiro, juntamente com a colaboração do professor Wanderley de Souza, importante cientista na área de Biofísica, juntaram-se com propósito de fundar a Universidade Aberta do Brasil - UAB unindo diversas universidades federais brasileiras, a qual não teve êxito na época como consórcio.

Após esse primeiro momento, o professor Wanderley de Souza sugeriu transformar a concepção da criação de um consórcio de universidades públicas do projeto Universidade Aberta do Brasil - UAB para o domínio de um consórcio de universidades públicas do Estado do Rio de Janeiro, sobrepondo esse plano em ação ao assumir como secretário a Secretaria de Estado de Ciência e Tecnologia do Rio de Janeiro.

O Cederj desde o início de suas atividades teve como objetivo oferecer cursos na modalidade à distância com a mesma eficiência dos cursos das universidades presenciais, de acordo com análise do Instituto Nacional de Estudos e Pesquisas Educacionais Anísio Teixeira - INEP.

A oferta de cursos de graduação Cederj teve início em 2001 com o curso de licenciatura 
em matemática pela Universidade Federal Fluminense - UFF, somente com 160 alunos alocados entre os pólos Itaperuna, Paracambi, São Fidélis e Três Rios. Já em 2017, o Cederj tem cerca de 40 mil alunos ativos distribuídos entre 32 Polos regionais do Estado do Rio de Janeiro, sendo o foco principal na criação do Cederj atender os alunos de localidades distantes que queriam estudar e não tenham condições de entrar em uma universidade.

Segundo Moran (2002), para ocorrer uma comunicabilidade adequada na educação à Distância é necessário recursos didáticos capaz de atender as necessidades dos materiais para estudo como: Apostilas, livros, CD-Rom, páginas Web, fóruns, teleconferências, vídeos, programas televisivos e radiofônicos. O material didático precisa dar autonomia para que 0 aluno possa aprender a controlar seu desenvolvimento.

O alunado dos cursos em EaD geralmente trabalham, estudam e fazem cursos complementares que exigem uma dedicação maior para realização de seus sonhos. Sua escolha pela EaD dá-se pelo fato da economia de tempo, possibilitando seu ingresso na educação e porque oferece condições e flexibilidade de horários motivando o aluno a estudar pela plataforma com a oferta de material de estudo gratuito, tornando-se um meio de inclusão na sociedade.

Conforme pesquisa feita sobre o Consórcio Cederj, foi constatado que o Polo Rocinha iniciou-se em janeiro de 2012 com a oferta de quatro cursos pela EaD, Licenciatura em Pedagogia (Universidade Estadual do Rio de Janeiro - UERJ), Tecnologia em Sistemas da Computação (Universidade Federal Fluminense - UFF), Administração (Universidade Federal Rural do Rio de Janeiro - UFRRJ) e Tecnologia em Gestão de Turismo (CEFET - RJ).

Até dezembro de 2013 o PED funcionou no local onde hoje funciona a 11를 Delegacia Policial Civil - DP - Rocinha. Em 25 de fevereiro de 2014, o Polo foi reinaugurado tendo um nova estrutura.

O Polo de Educação à Distância - PED Rocinha, fica situado à R. Bertha Lutz, 85 - São Conrado, Rio de Janeiro - RJ, 25450-290 - Telefone: (21) 2334-7099 e está aberto de terça à sexta de $13 \mathrm{~h}$ às $22 \mathrm{~h}$ e aos sábados de $9 \mathrm{~h}$ às $17 \mathrm{~h}$.

O curso de turismo e todos os outros cursos oferecidos pelo Consórcio dispõem de uma estrutura de apoio com três encarregados pela disciplina: coordenador, tutor presencial e tutor à distância.

No que diz respeito ao aluno, estes podem fazer uso da tutoria pela plataforma, ou central de atendimento (telefone) e também da tutoria presencial no Polo. 
Para Marconi e Lakatos (2003), a pesquisa exploratória é um processo refletido que e permite constatar novas informações em qualquer tempo oferecendo a oportunidade de conhecer uma determinada realidade ou mostrar veracidades de um projeto.

Através dessa pesquisa foi constatado que o Polo possui 1 secretaria do Polo Cederj; 1 secretaria do Centro de Educação de Jovens e Adultos (Ceja); 1 biblioteca; 1 auditório; 8 salas para aplicações de provas e tutoria; 2 laboratórios de informática com web estruturada conforme informações obtidas através do tutor presencial do curso de Tecnologia de Sistema de Computação - Sr. Luis Fernando Valentim; 1 banheiro feminino e 1 masculino; 1 copa e rampa de acessibilidade ao Polo para pessoas com deficiência - PCD's.

Segundo Brasil (2005 apud Gouvêa; Oliveira, 2006, p. 54), à Tecnologia da Informação e Comunicação - TIC é o principal fator da educação à distância porque os alunos podem desenvolver suas atividades educativas em locais, tempos e horários flexíveis contribuindo para o seu aprendizado e troca de saberes.

O artigo está estruturado em três seções a contar da introdução, apresentando uma visão geral do que é abordado no decorrer do trabalho, bem como os aspectos metodológicos adotados. Na segunda parte, é apresentado a metodologia do ensino à distância na realidade brasileira. A terceira parte diz respeito ao perfil do curso de ensino à distância: uma revisão da literatura assim como o perfil do curso Tecnológico em Turismo do CEFET - RJ. Nessa parte é exposto o tema Educação à Distância no curso de Gestão de Turismo do CEFET - Polo Rocinha onde se estabelecem as fundamentações e construção do tema assim como as considerações finais.

\section{Metodologia}

Para Vergara (2000), a pesquisa realizada pode ser considerada exploratória pelo fato de abrir questões de estudo em uma área mostrando pouco desenvolvimento, como também descritiva, ao expor o perfil do curso EaD de Tecnólogo em Turismo do CEFET/RJ - Polo Rocinha.

Segundo Marconi (2003, p.27), pesquisar, interpretar e entender, envolve estudos de referências bibliográficas, com apoio de artigos, teses e demais publicações acerca do tema para fundamentar, teórica e metodologicamente, o estudo. Em busca de referenciais teóricos para este estudo foram feitas pesquisas em bases de dados com palavra-chave como: educação à distância, Cederj, perfil do aluno na EaD. Após essa pesquisa com as palavras chaves sobre o assunto foram encontrados sete artigos 
científicos dissertando sobre o tema em questão com a finalidade de averiguar se constavam pesquisas que apontavam similaridade neste trabalho.

A princípio são apresentados conceitos da Educação a Distância do Cederj, este estudo, depende do consórcio formado pelas Universidades de diversas áreas juntamente com o poder público para concretizar a eficiência e demanda dos usuários.

Um dos principais desafios teóricos e práticos do século é a tecnologia na educação à distância. Com várias questões a serem discutidas a tecnologia moderna e seus desafios, a interação tecnológica e seu progresso causam efeitos no conceito do ser humano e na sociedade tecnológica, mais especificamente no que diz respeito à relação tecnologia e educação quão levam as artes do fazer, as profissões e o modo de realizar alguma coisa (COSTA E SILVA, 2005).

Para Brito, (2008, p. 23) existem várias situações nas quais a tecnologia é necessária para que as pessoas possam viver na sociedade moderna. $\mathrm{Na}$ atualidade todos precisam aprender, ensinar, comunicar, conhecer e integrar o humano com 0 tecnológico e o individual e o social.

Mercado (2002), menciona que cada vez mais é necessário a conscientização, e o reconhecimento da sociedade de incluir nos currículos escolares as competências e habilidades da tecnologia na educação a fim de apresentar uma abordagem diferenciada. Englobar novas tecnologias na educação contribui para novos conhecimentos acrescentando contextos entre ensinos e as culturas fora do âmbito escolar, facilitando o acesso a informações.

O Cederj - Centro de Educação a Distância do Estado do Rio de Janeiro - RJ, através de consórcio com diversas universidades oferece oportunidade de graduação em vários cursos distribuídos pelos 32 Polos existentes em diversas localidades para aqueles que estejam interessados em uma formação profissional.

O aluno estuda pela plataforma de acordo com sua disponibilidade de horário. Também tem os trabalhos que são enviados via plataforma através de links enviados pelo tutor da disciplina. Ressalta-se ainda que os Polos de Educação à Distância - PED oferecem tutorias presenciais e que as avaliações presenciais são nos finais de semana que constam no cronograma de atividades das disciplinas que é disponibilizado no início de cada semestre.

\section{Ensino à Distância na realidade brasileira}


Conforme pesquisa feita pelo Ministério da Educação e Cultura - MEC, a educação à distância é um meio de ensino que permite através de materiais didáticos, organizados e disponíveis levar conhecimento para todos por meio do alicerce da tecnologia (Art. 1 Art. $1^{\circ}$ do Decreto 2.494/98).

Em cursos de nível superior, na década de 1980 foi a Universidade de Brasília a primeira precursora em EaD no país (GOUVÊA; OLIVEIRA, 2006).

Com base na pesquisa feita (BRASIL, 2005), a EaD possibilita o ingresso de pessoas na educação porque oferece condições e flexibilidade de horários para estudar possibilitando o aluno adquirir conhecimentos pela plataforma, onde ele encontra conteúdo e material de estudo não gerando gastos para o estudante tornando-se um meio de inclusão na sociedade.

A EaD é formada por diversas gerações e no processo de regularização, no entanto ainda não temos um estudo concreto sobre o perfil dos alunos dessa modalidade. Conforme pesquisa no Instituto Nacional de Pesquisas Educacionais Anísio Teixeira INEP, em 2014 existiam mais de 1,2 mil cursos à distância no Brasil, sendo as universidades responsáveis por $90 \%$ da oferta. Ainda com estudo nessa mesma pesquisa foi constatado um crescimento de 49 mil para 1,1 milhão para os alunos EaD.

Em se tratando do Consórcio Cederj - Centro de Educação Superior a Distância do Estado do Rio de Janeiro, este surgiu da união entre o Governo do Estado do Rio de Janeiro, através Secretaria de Ciência e Tecnologia, das prefeituras do Estado do Rio de Janeiro e das universidades públicas consorciadas - UERJ, UFF, UFRJ, UENF, UFRRJ e UNIRIO, em 26 de janeiro de 2000.

A EaD aumenta sua universalização com Plano Nacional de Educação, conforme consta no Decreto no 5.622, de 19/12/2005, que regulamenta o Art. 80 que diz - "modalidade educacional na qual a mediação didático-pedagógica nos processos de ensino e aprendizagem ocorre com a utilização de meios e tecnologias de informação e comunicação, com estudantes e professores desenvolvendo atividades educativas em lugares ou tempos diversos" (BRASIL, 2005, apud GOUVÊA; OLIVEIRA, 2006, p. 54).

O CEDERJ designa-se a formação de profissionais em educação com formação em licenciatura assim como na formação de profissionais de nível Técnico.

\section{O perfil do ensino a distância: uma revisão da literatura}


Conforme Schnitman (2010), conhecer as características dos alunos que buscam a EaD contribui para a concepção de novas estratégias didático-pedagógicas, maior qualidade nos processos avaliativos e adequação de ambientes virtuais de aprendizagem.

Segundo Belloni (2006 p. 39), dependendo do enfoque dos padrões econômicos referente à perspectiva das volumosas definições, para saber qual é o perfil do aluno da EaD é preciso investigar algumas características que lhes são determinantes:

As características fundamentais da sociedade contemporânea que mais têm impacto na educação são, pois, maior complexidade, mais tecnologia, compressão das relações de espaço e tempo. Trabalho mais responsabilizado, mais precário, com maior mobilidade, exigindo um trabalhador multicompetente, multiqualificado, capaz de gerir situações de grupo, de se adaptar a situações novas, sempre pronto a aprender. Em suma, um trabalhador mais informado e autônomo. (BELLONI, 2006 P.39). O estudante que escolhe estudar pela $\mathrm{EaD}$ tem características próprias, que são essenciais para a percepção e conhecimento do mesmo com a finalidade de focar sua atenção por longos períodos de estudo conforme mencionou o presidente da Associação Brasileira de Educação a Distância - ABED, Frederic Michael Litto, em entrevista à Folha on-line com a repórter Camila Marques em 2004, onde reconhece que a modalidade EaD "não é para todos" sendo determinante o perfil do aluno.

Segundo Ramble (1992), um grande quantitativo de pessoas que se matriculam em curso a distância não planejam que tem de cumprir todas as tarefas, atividades e avaliações exigidas, e com isso gera um grande número de evasão que influencia no sucesso ou insucesso do curso a distância. Para Ramble (1992), uma parte dos alunos matriculados nos cursos nem chegam a começar o curso.

Verificou-se nesta revisão de literatura que o perfil dos alunos que estudam na modalidade a distância, é formado na maioria por adultos que encontraram na EaD uma alternativa acessível de continuar os estudos, ajustando suas ocupações profissionais e familiares.

\section{O perfil do curso EaD de Tecnólogo em Turismo do CEFET/RJ - Polo Rocinha}

Conforme pesquisa feita através da plataforma Cederj, duas vezes ao ano são abertas inscrições para o vestibular para os interessados nos cursos de graduação de Administração; Administração Pública; Disciplinas Pedagógicas, Engenharia de Produção; Licenciatura em Ciências Biológicas; Licenciatura em Física; Licenciatura em Geografia; Licenciatura em História; Licenciatura em Letras; Licenciatura em Matemática; Licenciatura em Pedagogia; Licenciatura em Química; Licenciatura em 
Turismo; Tecnologia em Gestão de Turismo; Tecnologia em Sistema de Computação e Tecnólogo em Segurança Pública e Social.

Os discentes do curso de Tecnologia em Gestão de Turismo (TGT) estudam 21 matérias, sendo 19 obrigatórias totalizando uma carga horária de 2.175 horas e 2 optativas que estejam na grade curricular totalizando 120 horas.

\section{Conclusão}

Ao finalizar a pesquisa, conclui-se que o principal objetivo é o estudo da EaD, nota-se que o principal fator determinante é a motivação do aluno para fazer o curso, à forma pela qual os professores conduzem suas atividades e pela facilidade de encontrar a ferramenta necessária para desenvoltura e interatividades nos acesso às atividades do curso a distância.

A estratégia do Consórcio Cederj é formar profissionais que estão geograficamente longe de universidades com regime presenciais, que dispõem de pouco tempo para 0 estudo, ou não possuem condições financeiras para matricular-se em universidades particulares.

O turismo é classificado como uma atividade que interfere na organização dos espaços de forma positiva como gerador de emprego e renda ou negativa, sendo assim, é necessário um planejamento para que se possa transformar a visita turística em uma experiência enriquecedora e agradável tanto para o turista como para a localidade.

Por fim, espera-se que este trabalho promova uma reflexão sobre o funcionamento de um PED e sua relevância dentro de um processo de ensino-aprendizagem em EaD. Pretende-se ainda que o estudo desperte iniciativas para a estudos de Polos de Educação à Distância em universidade públicas e privadas em todo território nacional.

\section{Referências}

BELLONI, Maria Luiza. Ensaio sobre a educação a distância no Brasil. Educação \& $\begin{array}{llllll}\text { sociedade, } & \text { v. } & 23, & \text { n. } & 78, & \text { p. }\end{array}$ http://www.scielo.br/pdf/es/v23n78/a08v2378.pdf Acesso em 10 mai 2018.

BIELSCHOWSKY, Carlos Eduardo. Consórcio Cederj: A História da Construção Projeto. EaD FOCO, v. 7, n. 2, 2017.

http://eademfoco.cecierj.edu.br/index.php/Revista/article/view/652/244 Acesso em 07 març 2018. 
COSTA, Gildemarks et al. A absolutização da póiesis: Vieira Pinto e o desafio da tecnologia no campo pedagógico. Fronteiras da Educação, v. 1, n. 1, 2011. https://docs. google.com/document/d/1uX3QToLhvvwzLJ9xZRoxOxoqpkldhNOtzXatXm5Kers/edit Acesso em 14 mai 2018.

LITTO, Fredric Michael; FORMIGA, Marcos (Ed.). Educação a distância: o estado da arte. Pearson, 2012. http://www.abed.org.br/arquivos/Estado_da_Arte_1.pdf Acesso em 05 mai 2018.

MARCONI, Marina de Andrade; LAKATOS, Eva Maria. Fundamentos de metodologia $\begin{array}{llll}\text { científica. } & 5 . & \text { ed.São } & \text { Paulo: }\end{array}$ https://docente.ifrn.edu.br/olivianeta/disciplinas/copy_of_historia-i/historia-ii/china-e-india - Acesso 06 mai 2018.

MATEUS BITTENCOURT, Ibsen; LEOPOLDO MERCADO, Luis Paulo. Evasão nos cursos na modalidade de educação a distância: estudo de caso do Curso Piloto de Administração da UFAL/UAB. Ensaio: Avaliação e Políticas Públicas em Educação, v. 22, n. 83, 2014. http://www.scielo.br/pdf/ensaio/v22n83/a09v22n83.pdf - Acesso em 18 mai 2018.

MERCADO, Luís Paulo Leopoldo et al. Formação docente e novas tecnologias. In: IV Congresso RIBIE, 1998. http://www.ufrgs.br/niee/eventos/RIBIE/1998/pdf/com_pos_dem/210M.pdf - Acesso em 14 mai 2018.

MORAN, José Manuel. O que é educação a distância. São Paulo, 2002. http://www.abed.org.br/hotsite/20-ciaed/pt/anais/pdf/115.pdf - Acesso em 15 mai 2018.

MORAN, José Manuel. A integração das tecnologias na educação. Salto para o Futuro, 2005.http://www.abed.org.br/hotsite/20-ciaed/pt/anais/pdf/115.pdf - Acesso 13 mai 2018.

Polo Rocinha ganha nova sede - Disponível em: http://cederj.edu.br/fundacao/polorocinha-ganha-nova-sede/ Acesso em 12 mai 2018.

SCHNITMAN, Ivana Maria. O perfil do aluno virtual e as teorias de estilos de aprendizagem. 3o Simpósio Hipertexto e Tecnologias na Educação: redes sociais e aprendizagem, v. 1, p. 1-10, 2010.https://scholar.google.com.br/scholar?hl=pt-BR\&as_sd $\mathrm{t}=0 \% 2 \mathrm{C} 5 \& \mathrm{q}=\mathrm{O}+$ perfil+do+aluno+virtual+e+as+teorias+de+estilos+de+aprendizagem\&bt $n G=$ Acesso em 28 abr 2018. 
Vestibular Cederj - Inscrições Disponível em http://cederj.edu.br/vestibular/cederjisencao-cota-2018/ - Acesso em 13 mai 2018.

VERGARA, Sylvia Constant. Começando a definir a metodologia. Projetos e relatórios de pesquisa em administração, v. 3, p. 46-53, 2000. https://docslide.com.br/documents/v ergara-sylvia-constant-projetos-e-relatorios-de-pesquisa-em-administracao.html Acesso em 13 mai 2018. 